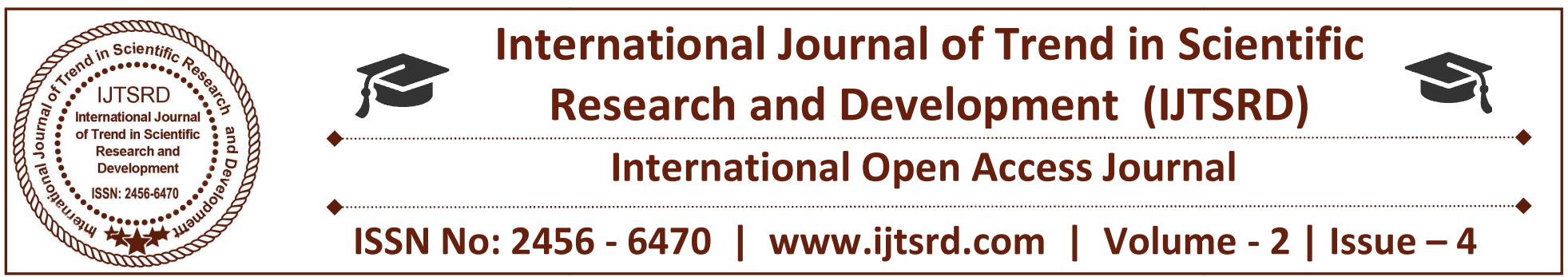

\title{
Nutraceuticals: New Concept of Medicines
}

\author{
Parvaiz Ahmad Parry*, Aadil Hussain Tantray, Aadil Mustafa, Shabir Ahmad Ganie \\ Department of Pharmaceutical Sciences, Mewar University, \\ Chittorgarh, Rajasthan, India
}

\author{
Mr Rajan Kothari \\ Assistant Professor, Department of Pharmaceutical Sciences, Mewar University, \\ Chittorgarh, Rajasthan, India
}

\begin{abstract}
A nutraceutical is a food or a part of a food stuff that provides medical or health benefits, including the avoidance and handling of diseases. The food products which are used as nutraceutical are Probiotic, Prebiotic, Dietary fiber, Omega 3 fatty acid, and antioxidants. Nutraceuticals have received significant attention due to their speculative safety, potential nutritive and therapeutic effects. Nutraceuticals are alternative to modern medicines and also provide healthy living. To avoid side effects associated with medicines, live longer expectation and to increase the health value of our diet, nutraceuticals are being preferred. They possess abundant therapeutic benefits like anti-obesity, immune enhancement, natural antioxidant, cardiovascular effects, anti-diabetic, antiinflammatory effects, etc. The main constituents of nutraceuticals are nutrients, herbals and dietary supplements which assist to maintain health, function against various diseases and ensure better quality of life. The aim of this article is to provide the current knowledge about the useful information about nutraceuticals.
\end{abstract}

Keywords: Nutraceuticals, functional foods, dietary supplements, phytochemicals, herbal, quality of life, probiotics

\section{INTRODUCTION}

"A nutraceutical is a food or a part of a food for oral administration with established protection and health benefits beyond the basic nutritional functions to supplement diet, presented in a nonfood medium or nonconventional food formats, in such a size that exceeds those that could be obtained from normal foods and with such rate as required to realize such properties, and is labeled as a ,nutraceutical ${ }^{e}$.[1] Nutraceuticals are diet supplements that carry a concentrated form of an alleged bioactive agent from a food, presented in a non-food matrix, and used with the reason of enhancing health in dosages that exceed those that could be obtained from normal foods.[2,3,4] They also refer to natural functional/medical foods or bioactive phytochemicals that have a number of health promoting, disease preventing or medicinal properties.[5,6] A nutraceutical is a product isolated or purified from foods that is generally sold in medicinal forms not usually associated with food.[7,8-10]

\section{CONCEPT OF NUTRACEUTICALS:}

In the pharmaceutical development procedure, it is a necessity to have clinical test results from animal tests and studies, for verification of the effects. On the other hand, in the case of nutrition, there were no authentication methods for foods in preventing diseases in the past. In current years however, as food composition has been scientifically demonstrated to cause living style-related diseases, and has become a social issue. The concept of Nutraceuticals has started to be approved as one of the measures for preventing such diseases. $[11,12,13,14]$. 


\section{PRESENT MARKET SCENARIO:}

Global nutraceuticals market size is expected to reach $\$ 302,306$ million by 2022 from $\$ 184,092$ million in 2015 with a CAGR of $7.04 \%$ from 2016 to 2022 . The global nutraceuticals product market holds a substantial scope for growth; however, its contribution to the global market is projected to increase significantly within the next six years. Nutraceuticals are versatile in nature as they are used in numerous industries such as pharmaceutical food \& beverages, animal feed additives, and personal care. Recent innovations and findings of function-specific antioxidants are expected to create new opportunities in this booming sector. Nutraceutical products are the necessity of the modern world. The market is poised to witness significant growth during the forecast period, owing to the increase in demand for preventive healthcare and rise in medical treatment, which stimulates the demand for nutraceuticalscontaining products. However, high investment for $R \& D$ is expected to hamper the market growth. Emerging innovations in this sector, which include novel Neem Extract and Purple corn, are the sources with more antioxidants than others. Developing economies are oriented toward preventive health care; hence, the demand for nutraceutical product increases significantly. In future, functional food \& beverages industries are anticipated to use antioxidants in excess. These are expected to contribute to the market growth.

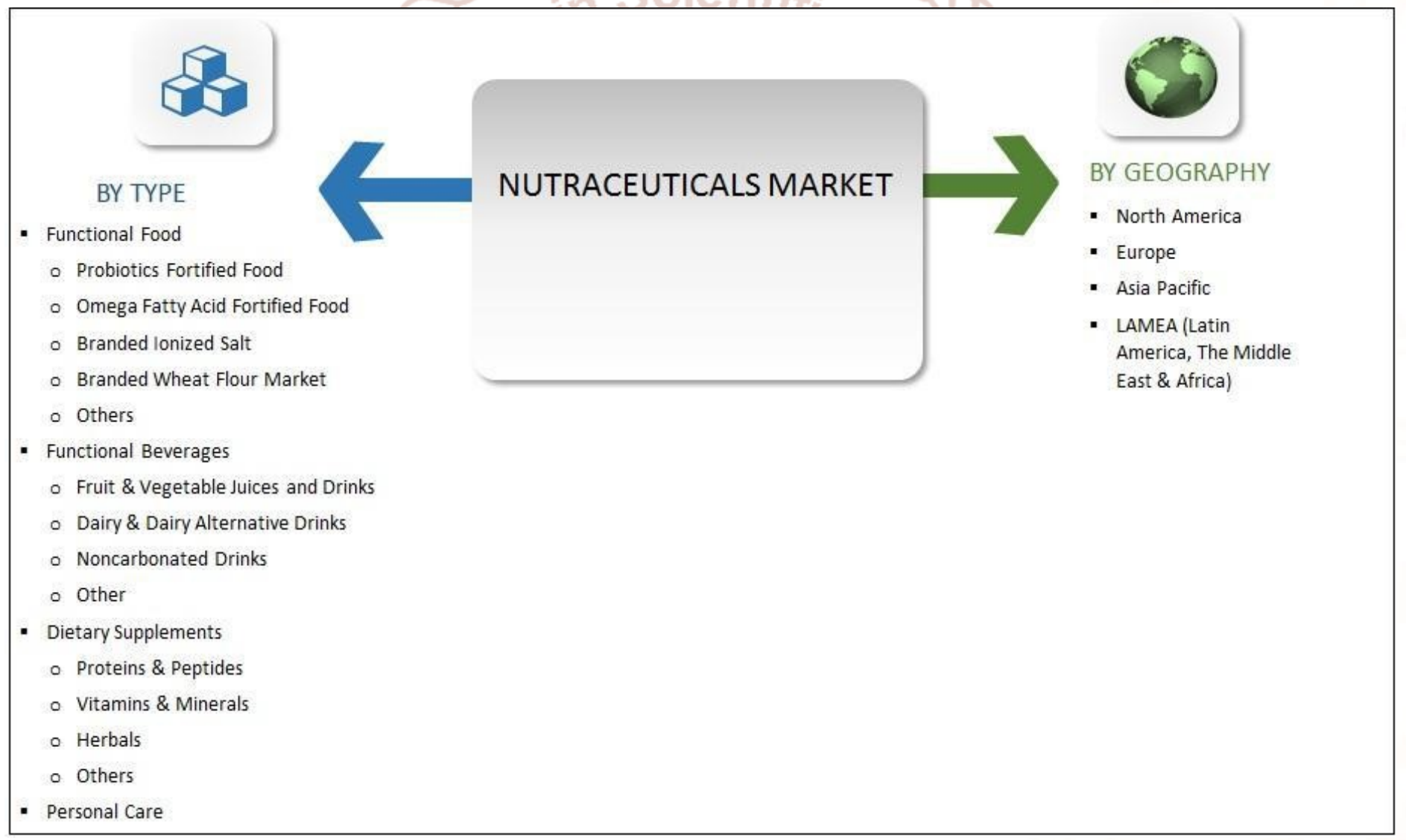

Figure 1. Segment Review:

The market is bifurcated based on type and geography. By type, nutraceuticals product market is divided into four types, namely, functional food, functional beverages, dietary supplements, and personal care. Functional food is further subsegmented into probiotics fortified food, omega fatty acid fortified food, branded ionized salt, branded wheat flour market, and other functional food. Functional beverages are further segmented into fruit
\& vegetable juices and drinks, dairy \& dairy alternative drinks, noncarbonated drinks (bottled water, tea, and coffee), and other (herbal tea, sports drinks, and energy drinks). In addition, dietary components comprise proteins \& peptides, vitamins \& minerals, herbals (Ayurveda extracts, plant extracts, algal extracts, and phytochemicals), and others (fatty acids and fiber). By geography, the market is segmented into North America, Europe, Asia-Pacific, 
and LAMEA. LAMEA region comprises of Latin America, Middle East, and Africa. High demand for electricity in the developing economies, such as Brazil and Middle-Eastern countries (Iran and Saudi Arabia) is the key growth factor for the nutraceuticals market. The nutraceuticals market in LAMEA is expected to grow at a CAGR of $7.39 \%$ between 2016 and 2022. The nutraceuticals market in Africa accounted for $\$ 2,527$ million in 2014 and is anticipated to garner $\$ 4,815$ million in 2022 expanding at a CAGR of $7.77 \%$ between 2016 and 2022. [15]

\section{TAPPING INDIA'S MARKET POTENTIAL:}

The nutraceuticals industry in India is one of the rapid growing markets in the Asia-Pacific region. According to a recent report, the nutraceuticals industry in India is worth about $\$ 2.2 \mathrm{bn}$ and is projected to grow at $20 \%$ to $\$ 6.1$ bn by $2019-2020$.

\section{LATEST TRENDS IN NUTRACEUTICALS FORMULATIONS IN INDIA:}

\section{Changing trends dosage forms}

Nutraceutical ingredients have typically been positioned as natural and healthy alternatives to allopathic medicines. However one of the primary challenges being faced by these products is the difficulty in formulating these products using the right dosage form. Besides, flavor and fragrance masking, the dosage forms also need to increase the stability of ingredients in the final product. But lately consumers are seeking more variety and benefits from delivery methods beyond those possible through traditional (tablet and capsule) technologies. As a result, the formulator needs to work far harder to cater to increasing consumer demands. As the nutraceutical industries look to carve a niche of their own and create a differentiated product, an important trend is the growth and diversity of new dosage formulations. As a result, traditional tablets and chewables are slowly being replaced by capsules, particularly liquidfilled capsules. [16]

\section{CLASSIFICATION OF NUTRACEUTICALS:}

Nutraceuticals is a broad umbrella term used to describe any product derived from food sources that provides the extra health benefits in addition to the basic nutritional value found in foods. Products typically claim to There is least regulation over which the products are allowed to display the nutraceutical term on their labels. Therefore, the term is often used to market products with varying uses and effectiveness and the definition of nutraceuticals and related products often depend on the source. The members of medical community desire that the nutraceutical term be more clearly recognized in order to distinguish between the wide varieties of products out there. There are various types of products that may fall under the category of nutraceuticals. $[17,18,19,20]$

\section{DIETARY SUPPLEMENTS:}

The dietary supplements, such as vitamin B supplement show above, are usually sold in pill form. A dietary supplement is product contains nutrients that are derived from food products are concentrated in liquid or capsule form. The Dietary Supplement Health and Education Act (DSHEA) of 1994 defined commonly what constitutes a dietary supplement. "A dietary supplement is a product taken by mouth that may contain a "dietary ingredient" intended to supplement the diet. The "dietary ingredients" in these products includes: vitamins, minerals, herbs or other botanicals, amino acids, and substances such as enzymes, organ tissues, glandulars, and metabolites. Dietary supplements can also be extracts or concentrates, and may be found in various forms such as tablets, capsules, softgels, gelcaps, liquids, or powders. Dietary supplements do not have to be approved by the United States Food and Drug Administration (USFDA) before marketing. Even if supplements claim to provide health benefits, products usually include a label that says: "These statements have not been evaluated by the Food and Drug Administration. This product is not proposed to diagnose, treat, cure, or prevent any disease." 


\section{FUNCTIONAL FOODS:}

Functional foods are designed to allow consumers to eat enriched foods close to their natural state, rather than by taking dietary supplements that are manufactured in liquid or capsule form. The functional foods have been either enriched or fortified, by a process called nutrification. This practice restores the nutrient contents in a food back to similar levels from before the food was processed. Sometimes, additional balancing nutrients are added, such as vitamin D to milk. Health Canada defines the functional foods as "ordinary food that has components or ingredients added to give it a specific medical or physiological benefit, other than a purely nutritional effect."'In Japan, the functional foods must meet three established requirements: foods should be;

(1)Present in their naturally-occurring form, not in capsule, tablet, or powder form;

(2)Consumed in diet as often as daily; and

(3)Regulate a biological process in hopes of preventing or controlling disease.

\section{MEDICAL FOODS:}

Medical foods are not available as an over-the counter (OTC) product to consumers. The FDA consider that medical foods to be "formulated to be consumed or administered internally under the supervision of a physician, and which is intended for specific dietary management of a disease or condition for which distinctive nutritional requirements, on the basis of recognized scientific principles, are established by medical evaluation."Nutraceuticals and supplements don't meet these requirements and are not classified as the Medical Foods. Medical foods can be taken through the mouth or through tube feeding. Medical foods are always designed to meet certain nutritional requirements for people diagnosed with specific health problems. Medical foods are regulated by the FDA and will be prescribed or monitored by the medical supervision.

\section{FARMACEUTICALS:}

According to a report written for the United States Congress entitled "Agriculture: A Glossary of Terms, Programs, and Laws", "(Farmaceuticals) is a melding of two words farm and pharmaceuticals. It refers to medically valuable compounds produced from the modified agricultural crops or animals (usually through biotechnology). Proponents believe that using crops and possibly even animals as pharmaceutical factories could have much more cost effective than conventional methods. $[21,22,23,24]$

\section{Examples:}

Broccoli may be helpful in the prevention of cancer. The following is shortened list of some foods with reported medicinal value:

Antioxidants: resveratrol from red grape products; flavonoids inside citrus, tea, wine, dark chocolate foods; anthocyanins found in berries, and Vitamin C.

Reducing hypercholesterolemia: [23] some soluble dietary fiber products are used such as psyllium seed husk.

Cancer prevention: broccoli (sulforaphane) and fiddleheads (Matteuccia Struthiopteus).

Improved arterial health: soy/clover
(isoflavonoids).

Lowered risk of cardiovascular disease: alphalinolenic acid from flax or chia seeds and Omega 3 fatty acids in fish oil. In addition, some botanical and herbal extracts such as ginseng, garlic oil, etc. have been developed as nutraceuticals. Nutraceuticals are often used as nutrient premixes or nutrient systems in the food and pharmaceutical industries.

\section{DEMAND OF NUTRACEUTICALS:}

The nutraceutical industry are categorizes under three main segments which include functional foods, dietary supplements, and herbal/natural products [25]. The most fast growing segments of the nutraceutical industry were dietary supplements $(19.5 \%$ per year $)$ and natural/herbal products (11.6\% per year). A food stuff (as a fortified food or a dietary supplement) that provides the health benefits, if indeed a claim was made that implied the medicinal benefit regarding a nutraceutical product, the product would be required to comply with the regulatory requirements for medicinal products, in respect of safety, efficacy, and quality testing and marketing authorization procedures. FDA regulated dietary supplements as foods to ensure that they were safe and healthy and that their labeling was truthful and not misleading [26-30].

\section{THE FUTURE OF NUTRACEUTICALS:}

Increasing awareness levels about fitness and health, spurred by media coverage are prompting the majority 
of people to show the way of healthier lifestyles, exercise more, and eat healthy. The growing nutraceutical market indicates that end users are seeking minimally processed food with extra nutritional benefits and their organoleptic value. This development, in turn, is propelling growth in the nutraceutical markets globally. The emerging nutraceuticals industry seems designed to occupy the landscape in the new millennium. Its remarkable growth has implications for the food, pharmaceutical, healthcare, and agricultural industries. Many scientists consider that enzymes represent another exciting frontier in nutraceuticals. "Enzymes have been underemployed... they're going to be a searing area in the future." Fermentation technology using microbes to make the new food products also represents potential. Global trends to healthy products cannot be upturned. Companies taking lead by investing strategically in science, product development, marketing and consumer education will not go unrewarded. [31]

\section{CONCLUSION:}

Nutraceuticals are medicinal foods that play a vital role in maintaining well being, enhancing health, modulating immunity and thereby prevent as well as treat some specific diseases. The role of nutraceuticals in cardio vascular disease (CVD) has been found to be active and quite effective in a various number of studies. Evidences indicate that mechanistic actions of natural compounds involves a wide range of biological processes, including activation : of antioxidant defenses, signal transduction pathways, cell survival-associated gene expression, cell proliferation and differentiation and preservation of mitochondrial integrity. It appears that these properties play a vital role in the protection against the pathologies of such chronic disease. So, to utilize the potential of nutraceuticals and provide their benefits to people, there should be a research community to develop nutraceuticals upto the utilizable level.

\section{REFERENCES:}

1) M.Prasad Palthur et al.International Journal of Pharmacy and Pharmaceutical Sciences, 2010; 2(3).

2) Espin JC, Garcia-Conesa MT, Tomas-Barberan FA. Nutraceuticals: facts and fiction. Phytochemistry, 2007; 68(22-24): 2986-3008.
3) Zeisel SH. Regulation of nutraceuticals. Science, 1999; 285(5435): 1853-1855.

4) Mechanick JI. The rational use of dietary supplements and nutraceuticals in clinical medicine. Mt Sinai J Med., 2005; 72(3): 161-165.

5) Dureja H, Kaushik D, Kumar V. Development in nutraceuticals. Indian Journal of Pharmacology, 2003; 35: 363-372.

6) Zhao J. Nutraceuticals, nutritional therapy, phytonutrients, and phytotherapy for improvement of human health: a perspective on plant biotechnology application. Recent Pat Biotechnol, 2007; 1(1): 75-97.

7) Health Canada, Ottawa, Ontario [Internet].Canada: Policy Paper - Nutraceuticals/Functional Foods and Health Claims on Foods; c2009 [cited 2009 August 30]. Available from: http://www.hcsc.

8) Barnes S, Prasain J. Current progress in the use of traditional medicines and nutraceuticals. Current Opinion in Plant Biology, 2005; 8: 324-332.

9) Samuel Saito, P.E Froehlich, Grace Gosmann, and Anabergold, Full validation of simple method for determination of Catechins and caffeine in Brazilian Green tea(Camellia Sinesis var.assamica) using HPLC . Chrmotographia, 04/, 2007; 65(9): 607-610.

10) K. Brandt, L.P. Christensen, J. Hansen-Møller, S.L. Hansen, J. Haraldsdottir, L. Jespersen, S. Purup, A. Kharazmi, V. Barkholt, H. Frøkiær, M. Kobæk-Larsen, Trends Food Sci. Technol, 2004; 15: 384-393.

11) Functional Foods in Japan, Medical Food News, May 1997 No.6 http://www.medicinalfoodnews. $\mathrm{com} / \mathrm{vol01} /$ issue2/japan

12) Brower V., Nutraceuticals: poised for a healthy slice of the healthcare market?, Nat. Biotechnol., $16,728-731$ (1998)

13) Zeisel S. H., Regulation of "Nutraceuticals.", Science, 285:185-186 (1999)

14) Whitman M., Understanding the perceived need for complementary and alternative nutraceuticals: lifestyle issues. Clin J Oncol Nurs., 5:190-194 (2001)

15) Allied market research. https://www.alliedmarketresearch.com/nutraceutic als-market 
16) http://www.nuffoodsspectrum.in/inner view sing le details.php?page $=1 \&$ content type $=\&$ vrtcl pan el $\mathrm{nm}=\&$ ele id=NOR 588b37ba948df4.78777381

17) Temple WJ and Gladwin KK. Fruits, vegetables, and the.Prevention of cancer: Research challenges. Nutrition. 2003;1 9: 467-470.

18) $\mathrm{Hu} \mathrm{FB}$ and Willett WC. Optimal diets for prevention of coronary heart disease. JAMA. 2002; 288: 25692578.

19) Houston MC. Nutraceuticals, Vitamins, Antioxidants, and Minerals in the Prevention and Treatment of Hypertension. Progress in Cardiovascular Diseases.2005; 47: 396-449.

20) Thanopolou E, Baltayiannis $\mathrm{N}$ and Lykogianni V. Nutritional aspects regarding lung cancer chemoprevention. J Buon.2006; 11: 7-20.

21) Nelson NJ. Purple carrots, margarine laced with wood pulp?Nutraceuticals move into the supermarket. J Natl CancerInst. 1999; 91: 755757.

22) German JB and Walzem RL. The health benefits of wine.Annual Review of Nutrition.2000;20: 561-593Research J. Pharm. and Tech. 1(4): Oct.Dec. 2008,, 338

23) Gulcin I, Mshvildadze V, Gepdiremen A, et al. The antioxidant activity of a triterpenoid glycoside isolated from the berries of Hedera colchica: 3-O(Bdglucopyranosyl)- hederagenin. Phytother Res. 2006; 20:130-134.
24) Agarwal BB, Kumar A and Bharti AC. Anticancer potential of curcumin: preclinical and clinical studies. Anticancer Res. 2003; 23: 363398.

25) Das L, Bhaumik E, Raychaudhuri U, Chakraborty R. Role of nutraceuticals in human health. J Food Sci Technol 2011.

26) Rishi RK, Nutraceutical: Borderline between food and drug. Pharma Review 2006. Available from:

27) http://www.kppub.com/ articles/herbal-safetypharmareview-004/ nutraceuticalsborderline between-foodanddrugs.html.

28) Nutrition business journal estimates (NBJ data). 18. Joanne B, linda AA, Phillipson DJ. Herbal medicines. 3rd ed. RPS Publishing; p. 48, 263.

29) http://www.horiba.com/scientific/products/particle characterization/applications/nutraceuticals.

30) FICCI study on Implementation of Food Safety and Standard Act 2006: An Industry Perspective. Available from: http://www.Indiaenvironmentportal.org.in/Files/food_s afety_study.pdf.

31) Nutraceutical Market and its Regulation. Available from: http: //www agrIfoodgateway.com/articles/nutraceuticalmarket-anditsregulation.

32) Manisha Pandey *, Rohit K Verma, Shubhini A Saraf, Nutraceuticals: new era of medicine and health, Vol.3 Issue 1, January-March 2010, ISSN 0974-2441. 